\title{
Tratamiento no antimicrobiano de infecciones
}

\author{
JORGE PÉREZ G.*
}

\section{Non antimicrobial agents treatment of infections}

Sepsis is a complex clinical syndrome whose frequency is increasing all over the world, partially due to the increasing prevalence of immunocompromised hosts, patients with chronic diseases and a prolonged life expectative of the general population, all factors that enhance the number of susceptible hosts. Nevertheless the development of intensive care medicine the mortality of its more feared complication, the septic shock, has not been reduced. From a long time ago investigators have tried to handle the physiopathological mechanisms involved, the inflammatory mediators, without obtaining favorable outcomes. In this article we review those non antimicrobial interventions that have yielded positive results: low dose corticosteroid treatment, intravenous immunoglobulin and activated recombinant C protein.

Key words: Sepsis; Non antimicrobial therapy; Corticosteroids; Immunoglobulin; Drotrecogin

El enfoque de este capítulo se centrará fundamentalmente en el manejo no antimicrobiano de la sepsis.

Para conocer la magnitud del problema hay cifras que son muy elocuentes y justifican el esfuerzo por encontrar un fármaco que cambie su pronóstico.

Se estima que en el ámbito mundial se producen aproximadamente 18 millones de casos de sepsis al año con un incremento de $1 \%$ anual.

A pesar de los avances en la terapia antimicrobiana y soporte médico, el shock séptico sigue siendo causa importante de mortalidad, las cifras varían entre 30 y $70 \%$.

En E.U.A. se producen 750.000 casos al año y 225.000 personas fallecen. Es la principal causa de muerte en UCI no coronaria. Los costos económicos bordean los 16,7 billones de dólares.

Para comprender mejor dónde se puede intervenir para controlar la compleja respuesta del organismo, el esquema siguiente sintetiza muy brevemente la fisiopatología de la sepsis (Figura 1).

Una vez que el agente infeccioso invade las barreras naturales e ingresa al organismo, se liberan endotoxinas en el caso de las bacterias Gram negativas, o exotoxinas y productos derivados de la pared bacteriana en el caso de las bacterias Gram positivas, que actúan a nivel de macrófagos, estimulando la liberación de los me- diadores de la inflamación: fundamentalmente factor de necrosis tumoral alfa e interleukina-1. Estos mediadores van a actuar a distintos sitios: cascada de la coagulación, activación del ciclo de las prostaglandinas y activación del complemento. El resultado final es un daño endotelial que redundará en daño a un órgano, a un sistema, y si se asocia a compromiso hemodinámico, shock y finalmente falla multiorgánica y la muerte.

En un intento por frenar esta cascada se ha intentado actuar a distintos niveles de este proceso. La Tabla 1 resume los ensayos que se han efectuado y su sitio de acción.

Salvo los ensayos que se han efectuado con corticosteroides y proteína $\mathrm{C}$ activada, ninguno de las otras intervenciones ha demostrado algún beneficio. Existen ensayos con anticuerpos monoclonales contra FNT y con antagonistas de receptor de interleukina-1 que han reclutado una gran cantidad de pacientes pero cuyos resultados no han tenido significado estadístico, por lo que ninguno de ellos se recomienda. En un metaanálisis publicado en Critical Care Medicine del año $1997^{3}$ se analizan los ensayos más significativos y el resultado combinado de ellos no ofrece beneficio.

Corticosteroides: Los corticosteroides se han utilizado para el manejo de la sepsis desde los años $50 \mathrm{y}$ su uso se fundamenta en las siguientes 
propiedades:

- Mantención del tono vascular e integridad endotelial.

- Potencia la acción vasoconstrictora de las catecolaminas.

- Inhibe la producción de FNT, IL1 , NO sintetasa, FAP.

- Acción antiinfamatoria por inhibición de síntesis de prostaglandinas.

- Previenen la activación de la cascada del complemento.

- Previene la agregación y adhesión de leucocitos inducidos por endotoxina.

Al respecto existen muchos trabajos que intentan demostrar su utilidad; sin embargo, estudios bien diseñados randomizados comparativos hay muy pocos. Existen en la literatura dos metaanálisis efectuados en el año 1995 que evalúan el uso de corticosteroides en sepsis y shock séptico. Se revisaron 124 publicaciones entre los años 1966 y 1993 y se seleccionaron sólo 9 trabajos que cumplían con los criterios y que involucraban a 1.232 pacientes. Ambos meta-análisis prácticamente consideraron los mismos trabajos. El análisis combinado de todos los trabajos favorece el uso de placebo como se demuestra en el Gráfico 1.

La conclusión de este trabajo es que no hay beneficio del uso de corticosteroides en la sepsis y en el shock séptico ${ }^{1}$. Sin embargo, un análisis más detallado de estos trabajos permite obtener algunas conclusiones:

- En algunos de los estudios los corticosteroides fueron beneficiosos cuando se usaron oportunamente.

- La sepsis causada por bacilos Gram negativos responde mejor que otras infecciones

- Hay claro beneficio de corticosteroides en: meningitis bacteriana aguda, fiebre tifoidea, neumonía por Pneumocystis jiroveci (ex carinii) y SDRA.

Estos hallazgos motivaron el trabajo de Bollaret. Este es un estudio doble ciego randomizado, placebo, controlado, usando dosis de $300 \mathrm{mg}$ de hidrocortisona en pacientes con shock séptico . Se randomizaron 41 pacientes (22 tratamiento y 19 placebo). Como resultado se observó la reversión del shock a los 7 días: $68 \%$ en el grupo con tratamiento versus $21 \%$ en el grupo placebo, y una reducción en la mortalidad a los 28 días: $32 \%$ y $63 \%$ respectivamente.

Las explicaciones a estos resultados tan discordantes con las publicaciones previas se basan en que en los estudios previos se usó corticosteroides muy precozmente y a dosis suprafarmacológicas y por períodos muy breves.

Estos resultados junto al concepto de que en la sepsis existe una insuficiencia suprarrenal relativa motivaron un nuevo estudio por Annane et $\mathrm{al}^{2}$ que se ha constituido en el referente en el tema. Este es un estudio multicéntrico, doble ciego, randomizado, placebo, controlado, efectuado en 300 pacientes con criterios de shock séptico. Los pacientes fueron sometidos a un test de corticotropina. Luego randomizados a recibir $50 \mathrm{mg}$ de hidrocortisona ev cada 6 horas más $50 \mathrm{mg}$ de fludrocortisona al día ó placebo durante 7 días. Como resultado hubo 229 no respondedores y 70 respondedores al test de corticotropina. De los pacientes que no respondieron al test y por tanto, portadores de insuficiencia suprarrenal, 115 recibieron placebo de los cuales fallecieron 73 (63\%) y 114 recibieron corticoesteroides de los cuales fallecieron 60 $(53 \%)$.

De los respondedores 34 recibieron placebo falleciendo 18 (53\%), y 36 recibieron corticosteroides 
Tabla 1. Estrategias empleadas para intentar neutralizar el shock séptico

\begin{tabular}{ll}
\hline Ensayo terapéutico & Nivel de acción \\
\hline $\begin{array}{l}\text { Inmunoglobulina } \\
\text { Corticosteroides }\end{array}$ & Respuesta inmune \\
Anticuerpos anti endotoxina & LPS \\
BPI & \\
Ac. Anti FNT & FNT \\
Receptor soluble de FNT & \\
Antagonista de receptor de IL1 & IL1 \\
Antagonista de FAP & FAP \\
N-acetilcisteina & Radicales de O ${ }_{2}$ \\
Inhibidores de NO & NO \\
Azul de metileno & \\
Anti trombina III & Sistema de coagulación \\
TFPI & \\
Pca & Fosfodiesterasa \\
G-CSF M-CSF & Activación de neutrófilos \\
Antagonistas de bradiquininas & \\
Pentoxifilina & \\
\hline & \\
\hline
\end{tabular}

falleciendo $22(61 \%)$.

El análisis en todo el grupo arrojó el siguiente resultado: placebo 91 fallecidos $(61 \%)$ y corticosteroides 82 fallecidos $(55 \%)$. La conclusión de este trabajo es que hay un beneficio estadísticamente significativo en la mortalidad a los 28 días con el uso de bajas dosis de corticosteroides durante 7 días en aquellos pacientes que cursan con shock séptico e insuficiencia suprarrenal relativa, definida por una respuesta inadecuada a la estimulación con corticotropina. La recomendación de este autor es que a pacientes con shock séptico se les efectúe un test de corticotropina rápido y se le inicie corticoterapia. Si el resultado revela que existe insuficiencia suprarrenal relativa, recomienda continuar con los corticosteroides, si el paciente tiene una respuesta adecuada al test, se puede suspender el fármaco.

Inmunoglobulina: Alteraciones inmunológicas en pacientes con sepsis severa pueden ser responsables de la incapacidad para controlar la infección: deteriorada fagocitosis y disminución de la capacidad de opsonización del suero. Fundamentos teóricos para su uso son: - Neutralización de endotoxinas, exotoxinas y otras sustancias bacterianas.

- Neutralizar componentes del com-

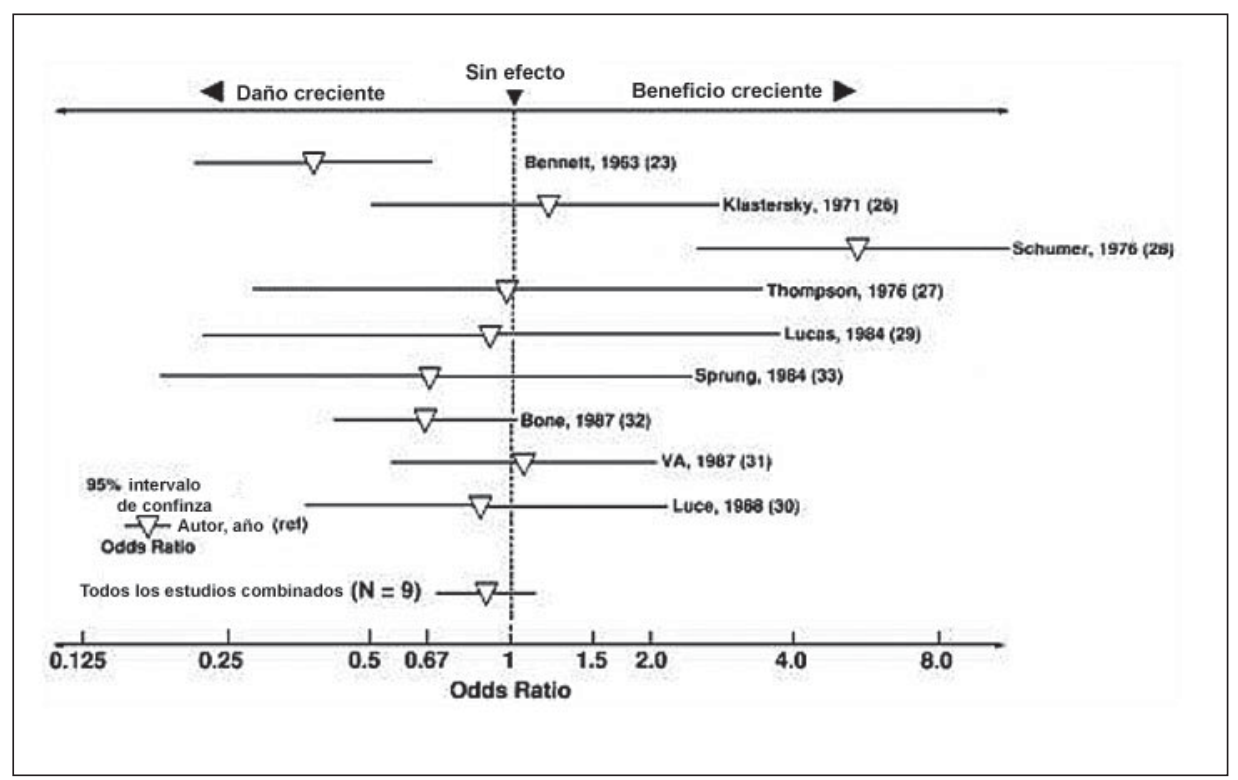

Gráfico 1. Meta-análisis del efecto de la corticoterapia en la resolución del shock séptico (referencia 1) 
plemento y lipopolisacaridos.

- Estimular actividad opsónica y bactericida del suero

- Reducir mediadores pro inflamatorios.

- Aumentar los mediadores antiinflamatorios.

Respecto a la evidencia de su uso en sepsis y shock séptico, una revisión en The Cochrane Database of Systematic Review del año $2003^{4}$ que utilizó los siguientes criterios de inclusión: ensayos randomizados que comparan inmunoglobulina (monoclonal o policlonal) con placebo o no intervención en pacientes con sepsis o shock séptico, 27 trabajos cumplían criterios con un total de 8.856 pacientes. La mortalidad disminuyó en pacientes que reciben inmunoglobulina policlonal. Para los dos más importantes ensayos el RR para mortalidad fue de 0,30. La mortalidad no se redujo en pacientes que recibieron anticuerpos monoclonales.

Conclusión: Todos los trabajos demuestran que la inmunoglobulina policlonal tiene un efecto beneficioso, inmunoglobulina monoclonal no tiene efecto favorable. Estos resultados deben interpretarse con precaución ya que todos los ensayos contemplan un número pequeño de pacientes y son necesarios ensayos más extensos para hacer una clara recomendación de su uso.

Intervenciones sobre la coagulación: Las alteraciones de la coagulación en la sepsis resultan en un estado pro coagulante que puede manifestarse como una coagulación intravascular diseminada (CID). Ensayos para revertir el estado de hipercoagulabilidad se han efectuado con diversos fármacos de los cuales los más representativos son: antitrombina inhibidor natural de la trombina y que está disminuida en la sepsis, inhibidores del factor tisular y proteína $\mathrm{C}$ recombinante activada. De éstas la única que ha demostrado un efecto beneficioso es la proteína $\mathrm{C}$ recombinante activada cuyo nombre genérico es drotrecogin alfa y su nombre comercial es Xigris ${ }^{\circledR}$. La proteína $\mathrm{C}$ activada tiene propiedades antitrombóticas, fibrinolítica y antiinflamatorias.

A continuación se describe el ensayo clínico que permitió demostrar su eficacia en el manejo de la sepsis y el shock séptico ${ }^{5}$.

Es un ensayo clínico multicentrico, doble ciego, randomizado, placebo-controlado, con los siguientes criterios de inclusión:

- Sitio conocido o sospechoso de infección

- 3 o más signos de inflamación sistémica durante 24 horas.

- Disfunción de al menos un órgano ó sistema de menos de 24 horas de duración, los pacientes fueron randomizados en una propor- ción $1: 1$ a recibir drotrecogin alfa activada o placebo. La dosis de drotrecogin alfa fue de 24 microgramos $/ \mathrm{kg} / \mathrm{hr}$ y se infundió durante 96 horas. El seguimiento fue por 28 días. Para evaluar su eficacia, el end point fue la mortalidad, de cualquier causa, a los 28 días. El ensayo fue diseñado para randomizar 2.280 pacientes.

Resultados: Recibieron placebo 840 pacientes, de los cuales fallecieron 259 (30,8\%). Recibieron drotrecogin alfa activado 850 pacientes, de los cuales fallecieron 210 (24,7\%). Hay una reducción absoluta del riesgo de muerte de $6,1 \%$, siendo la disminución del riesgo relativo de muerte de $19,4 \%$. Las diferencias son estadísticamente significativas. Si se agrupan los pacientes por score de APACHE se observa que cuando el puntaje es mayor a 24 la reducción absoluta de la mortalidad es de $13 \%$. Estos resultados hicieron suspender precozmente el estudio y se enrolaron 1.728 pacientes siendo 1.690 los sometidos a análisis.

Estos resultados son bastante significativos si se comparan con los obtenidos en otros grandes ensayos por ejemplo en cardiología donde el estudio GISSI-streptokinasa para infarto agudo del miocardio (IAM) reduce la mortalidad absoluta en 2,3\%, ISIS-2-streptokinasa + ácido acetilsalicílico para IAM reduce la mortalidad absoluta en $5,2 \%$. Usando los mismos datos se necesitan en el estudio GISSI tratar 43 pacientes para salvar una vida, en el ISIS-2 19 pacientes. En el estudio con drotrecogin alfa 16 pacientes, y si consideramos sólo pacientes con APACHE II $>$ a 24 , sólo se requiere tratar 8 pacientes para salvar una vida. Drotrecogin alfa fue aprobada por la FDA en noviembre de 2001.

En la revista Critical Care de diciembre de $2002^{6}$ se publicaron las conclusiones de una reunión de consenso en donde participaron destacados médicos intensivistas para establecer criterios de manejo de la sepsis y el shock séptico, en base a la evidencia. Sus recomendaciones fueron las siguientes:

- Ventilación mecánica con uso de volúmenes corrientes pequeños.

- Manejo hemodinámico precoz.

- Manejo muy estricto de la glicemia.

- Uso de corticosteroides en dosis bajas.

- Uso de proteína C activada.

\section{Resumen}

La sepsis es un complejo síndrome que puede progresar a la falla multiorgánica y a la muerte. A pesar de todos los avances sigue teniendo alta 
mortalidad y constituyendo una importante carga económica. Además del manejo hemodinámico ventilatorio y metabólico existe evidencia para incorporar el uso de corticosteroides y proteína $\mathrm{C}$ activada. El control de la sepsis en el futuro está en la interrupción de la cascada inflamatoria. El manejo de sólo una de las vertientes de esta respuesta está destinado al fracaso.

\section{Bibliografía}

1.- Cronin L, Cook D J, Carlet J. Corticosteroid treatment for sepsis: A critical appraisal and meta-analysis of the literature. Crit Care Med 1995; 23 (8): 1430-9.

2.- Annane D, Sebille V, Charpentier C. Effect of treatment with low doses of hydrocortisone and fludrocortisone on mortality in patient with septic shock. JAMA 2002; 288 (7): 862-71.

3.- Zeni F, Freeman B, Natanson C. Anti-inflammatory therapies to treat sepsis and septic shock: A reassessment. Crit Care Med 1997; 25 (7): 1095 100 .

4.- Alejandria M M, Lansang M A, Dans L F. Intravenous immunoglobulin for treating sepsis and septic shock. The Cochrane Database of Systematic Review.Vol(1) 2003.

5.- Bernard G, Vincent J L, Laterre P-F. Efficacy and safety of recombinant human activated protein $\mathrm{C}$ for severe sepsis. N Engl J Med 2001; 344(10): 699-709.

6.- Vincent J-L, Abraham E, Annane D, Bernard G, Rivers $\mathrm{E}$ and Van den Berghe G. Reducing mortality in sepsis: new directions. Crit Care 2002; 6 (Suppl 3 ): S1-8. 